\title{
Erratum
}

Immunogenetics 29: 191-201, 1989

\section{Restriction fragment length polymorphisms of the mouse T-cell receptor gene families}

\author{
J. L. Klotz ${ }^{1}$, R. K. Barth ${ }^{2}$, G. L. Kiser ${ }^{1}$, L.E. Hood $^{3}$, and M. Kronenberg ${ }^{1}$ \\ ${ }^{1}$ Department of Microbiology and Immunology, UCLA School of Medicine, University of California, Los Angeles, CA 90024, USA \\ 2 Cancer Center and Department of Microbiology and Immunology, University of Rochester, Rochester, NY 14642, USA \\ ${ }^{3}$ Division of Biology, California Institute of Technology, Pasadena, CA 91125, USA
}

Table 6 on page 198 contains two errors. C58/J and SB/Le mice should be listed as members of Group II rather than Group I. 